\title{
Congenital heart defects in Williams syndrome
}

\author{
Shi-Min Yuan \\ Department of Cardiothoracic Surgery, The First Hospital of Putian, Teaching Hospital, Fujian Medical University, Putian, \\ Fujian Province, People's Republic of China. E-mail: shiminyuan@126.com \\ Received: 6th April 2017, Revised: 25th June 2017, Accepted: 4th July 2017
}

SUMMARY: Yuan SM. Congenital heart defects in Williams syndrome. Turk J Pediatr 2017; 59: 225-232.

Williams syndrome (WS), also known as Williams-Beuren syndrome, is a rare genetic disorder involving multiple systems including the circulatory system. However, the etiologies of the associated congenital heart defects in WS patients have not been sufficiently elucidated and represent therapeutic challenges. The typical congenital heart defects in WS were supravalvar aortic stenosis, pulmonary stenosis (both valvular and peripheral), aortic coarctation and mitral valvar prolapse. The atypical cardiovascular anomalies include tetralogy of Fallot, atrial septal defects, aortic and mitral valvular insufficiencies, bicuspid aortic valves, ventricular septal defects, total anomalous pulmonary venous return, double chambered right ventricle, Ebstein anomaly and arterial anomalies. Deletion of the elastin gene on chromosome $7 \mathrm{q} 11.23$ leads to deficiency or abnormal deposition of elastin during cardiovascular development, thereby leading to widespread cardiovascular abnormalities in WS. In this article, the distribution, treatment and surgical outcomes of typical and atypical cardiac defects in WS are discussed.

Key words: aortic valve stenosis, congenital heart defects, Williams syndrome.

Williams syndrome (WS), also known as Williams-Beuren syndrome, is a rare genetic disorder characterized by infantile hypercalcemia, short stature, a varying degree of mental retardation, elfin like facial features, a friendly and outgoing personality and cardiovascular abnormalities caused by a chromosome 7 microdeletion ${ }^{1}$. The most common congenital heart defects are supravalvular aortic stenosis (SVAS), followed by supravalvular pulmonic stenosis $^{2}$. In children with WS, SVAS is seen in $80 \%$ of cases; whereas about $50 \%$ of SVAS patients have $\mathrm{WS}^{3}$. Retrospective studies on larger series of WS patients revealed that peripheral pulmonary stenosis and SVAS were the two most common associated cardiovascular abnormalities (Table I).

Of those with cardiac anomalies, $34.5 \%$ had a single defect and $65.5 \%$ had multiple defects ${ }^{2}$. The mean age at diagnosis of the cardiac anomaly was 4.2 years, while the mean age at diagnosis of the syndrome was 6.2 years $^{6}$. Among patients with mild or absent significant cardiac findings, the mean age at diagnosis was 7.1 years; whereas among patients with
SVAS or severe cardiac symptoms, the mean age at diagnosis was 4.5 years $^{2}$. However, the etiologies of the associated congenital heart defects in WS patients have not been sufficiently elucidated and thus represent therapeutic challenges. In this article, the distribution, treatment and surgical outcomes of typical and atypical cardiac defects of WS are discussed.

\section{Etiologies}

Most WS cases were sporadic, while only a few were familial. Nevertheless, both sporadic and familial cases are considered as a result of deletion of chromosome 7 (7q11.23) ${ }^{7}$. Deletion of the elastin gene on chromosome 7q11.23 leads to deficiency or abnormal deposition of elastin during cardiovascular development, leading to widespread cardiovascular abnormalities in $\mathrm{WS}^{8}$. The chromosomal region has been designated as "Williams-Beuren Syndrome chromosome region 1" (WBSCR1). Theoretically, causative genes for WS are the ELN (elastin), LIMK1 (or LIM kinase-1), and RFC2 (replication factor C, subunit 2) genes ${ }^{7}$. The LIMK1 gene is 
believed to be responsible for the visual-spatial problems in WS patients ${ }^{7}$. Deletion of ELN and contiguous genes, mutations within the elastin gene result in two different autosomal dominant disorders, SVAS and cutis laxa ${ }^{9}$. Point mutations of elastin in exons $3,17,21,25$, and 26 in SVAS kindreds ${ }^{10}$, deletion of the 30 end at exon 27, in one family ${ }^{11}$, and a $30-\mathrm{kb}$ intragenic deletion of exons 2 through 27 , in an additional kindred ${ }^{12}$ were reported. These data proved that ELN mutations caused SVAS $^{13}$. Debates remain in terms of etiologies of vasculopathy in WS, on either by decrease of the synthesis of elastin ${ }^{14}$, or by abnormal deposition of elastin in the arterial walls ${ }^{8}$. Both were explained to be a pathway leading to thickening of the tunica media and smooth muscle cell hypertrophy ${ }^{14}$. Accordingly, these changes might result in classic cardiovascular manifestations in WS; the most common of which would be SVAS, hypoplasia of the aortic arch and pulmonary artery stenosis ${ }^{15}$. The pathological finding of the disorganized medial elements in the aortic tissues of WS patients with SVAS might partly interpret its developmental mechanism ${ }^{16}$.

\section{Typical cardiac defects}

According to a clinical study by Del Pasqua et al. ${ }^{6}$, typical cardiac defects were present in 94 of the 113 patients (83\%) and atypical defects were present in 19 patients (17\%). They also reported that among typical congenital heart defects SVAS was found in 73 of 113 patients $(64.6 \%), 58.9 \%(43 / 73)$ of which were an isolated SVAS. Pulmonary stenosis (both valvular and peripheral) was found in 51 of $113(45.1 \%)$ and in 18 cases, pulmonary stenosis was isolated, while aortic coarctation and mitral valvar prolapse were each found in $7(6.2 \%), 3$ of the lesions were in isolation ${ }^{6}$.

\section{SVAS}

As reported by Bruno et al. ${ }^{17}$, SVAS was the most frequent malformation representing $71 \%$ of cases, with $56.3 \%$ (18/32) having a moderate or severe stenosis and $34.4 \%(11 / 32)$ having diffuse lesions. They reported that 24 surgical or catheter interventions were required in 21 of their patients. Of the 18 patients with a moderate or severe SVAS, 16 (88.9\%) warranted surgical treatment ${ }^{17}$, and they found that aortic reconstruction was associated with a $12.5 \%(2 / 16)$ mortality in SVAS patients, and recurrent SVAS developed in $7.7 \%(1 / 13)$ survivors ${ }^{17}$. The surgical techniques for SVAS include McGoon's single-patch repair, Doty's pantaloon-fashion two-patch method, Brom's three-patch technique and Myer's autologous sliding aortoplasty.

By several comparative studies between the surgical techniques for SAVS in WS patients in terms of long-term prognosis, either by onepatch (McGoon technique), two-patch (Doty technique), or three-patch (Brom technique) aortoplasties, Fricke et al. ${ }^{18}$ and Cruz-Castañeda et al. ${ }^{19}$ revealed that the reoperation rate was the highest in those patients with McGoon repair, late results of Brom's technique were good and Myer's autologous sliding aortoplasty seemed to be the most promising (Table II). Kaushal et al. ${ }^{20}$ pointed out that the surgical indications for reoperation were residual aortic stenosis, aortic insufficiency and subvalvular stenosis. In contrast, Croti et al. ${ }^{22}$ demonstrated that SVAS patients receiving the Doty or Brom technique rarely required aortic reoperations, as for their low incidence of aortic regurgitation and an expanded ascending aorta without gradient as well as good ventricular performance. Moreover, Bonini et al. ${ }^{23}$ once introduced modified Sousa technique for the surgical repair of SVAS, but this has not been used in WS patients. In addition, SVAS in adult can also be managed with aortic valve replacement and arterioplasty of the ascending aorta, which have been performed by Valente et al. ${ }^{24}$. In general, the overall early mortality was very low, the late mortality ranged between $0 \%$ and $26 \%$, and survival was $95-98 \%$ at 5 years as reported by Deo et al. ${ }^{25}$. They indicated that predictors of late mortality might include male gender, poor NYHA heart function, type of SVAS, concomitant anomalies, remarkable preexisting aortic stenosis, an elevated residual postoperative gradient and younger age at operation $^{25}$.

\section{Pulmonary stenosis}

It has been reported by Bruno et al. ${ }^{17}$ that in WS, the incidence of pulmonary stenosis at the valvular level was $11 \%$, and they ${ }^{17}$ and Eronen et $a .^{26}$ reached consensus that the incidence of pulmonary artery stenosis was around $40 \%$. Del Pasqua et al. ${ }^{26}$ proposed that the major surgical or interventional indication for pulmonary stenosis in WS patients was a 
Table I. Associated Cardiovascular Abnormalities of Williams Syndrome ${ }^{4,5}$

\begin{tabular}{ll}
\hline Associated cardiovascular abnormalities & Percentage (\%) \\
\hline Aortic stenosis (supravalvular, valvular, or subvalvular) & $61-72$ \\
Pulmonary stenosis (valvular or peripheral) & $39-45$ \\
Systemic hypertension & 17 \\
Mitral valve prolapse & 15 \\
Coarctation of the aorta & 4 \\
Bicuspid aortic valve & 3 \\
Hypoplasia of the aorta & 2 \\
\hline
\end{tabular}

mean pressure gradient of $>45 \mathrm{mmHg}$. Clinical studies by different surgical teams, including Stamm et al. ${ }^{27}$, Monge et al. ${ }^{28}$ and Geggel et al. ${ }^{29}$ that the treatment of choice for pulmonary stenosis depended on the site of the lesion and the late results were fine (Fig. 1).

\section{Coarctation of the aorta}

Marks et al. ${ }^{30}$ described that coarctation repair was more commonly required in WS patients during neonatal period. The treatment of choice depended on patient's age and the situation of the coarctation of the aorta. Other authors, like Mannarino et al. $^{31}$ and Kammache et al. ${ }^{32}$ recommended that the open aortoplasty was indicated in the neonates and infants with discrete coarctation of the aorta and those patients with failed balloon dilation, but recoarctation rate was high. Ar1 et al. ${ }^{33}$ suggested that the subclavian flap aortoplasty technique for recoarctation after end-to-end anastomosis technique for

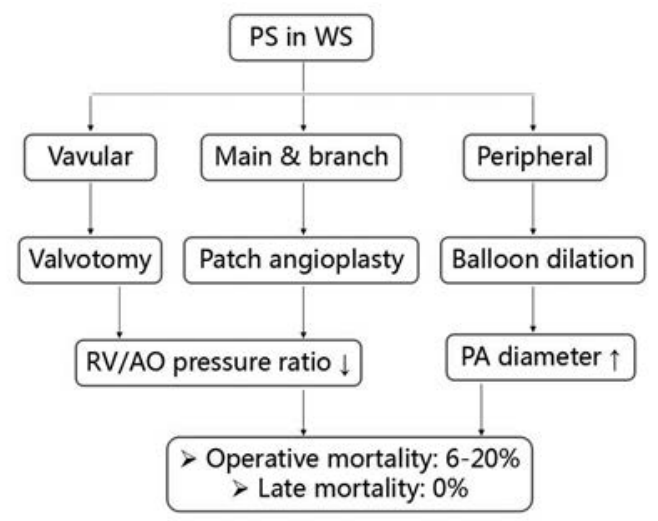

Fig. 1. Management of the associated pulmonary stenosis. AO: aorta; PA: pulmonary artery; PS: pulmonary stenosis; RV: right ventricle; WS: Williams syndrome. coarctation and subsequent failed balloon dilation angioplasty should be indicated for the patients with a rapidly progressive form of aortic coarctation. Apostolopoulou et al. ${ }^{34}$ once reported an aggressive surgical procedure including resection of the isthmus, removal of the stent, and end-to-end anastomosis to treat obliterated stent was performed with success in a patient with recoarctation. Moreover, Marks et al. ${ }^{30}$ reported a composite left subclavian artery flap and allograft patch aortoplasty of the aortic arch and descending aorta was performed through a left thoracotomy under cardiopulmonary bypass and circulatory arrest was successfully performed in a $2.7-\mathrm{kg}$ neonate.

Burrows ${ }^{7}$ proposed that dilations of the aortic arch and stent placement were indicated for those patients with coarctation of the aorta especially with diffuse hypoplasia of the aorta. As Apostolopoulou et al. ${ }^{34}$ illustrated that stent placement might be the treatment of choice for recoarctation in older patients; but Zanjani et al. ${ }^{35}$ indicated that, when massive neointimal proliferation was present, stent insertion became impossible. The reason of failure of end-to-end anastomosis and balloon dilation was considered by Mannarino et al. ${ }^{31}$ the consequence of an irregular elastic fiber arrangements of the aortic wall associated with the elastin mutation.

\section{Mitral valve disorder}

The incidence of mitral valve disease was reported by Scheiber et al. ${ }^{2}$ and by Bajracharya et al. ${ }^{36}$ to be $37-41 \%$ in WS patients, while the incidence of mitral valve prolapse was reported by Hallidie-Smith et al. ${ }^{37}$ to be $15 \%$. Takagi et al. ${ }^{38}$ observed that the mitral valve prolapsed in 
Table II. A Comparison of the Outcomes of Surgical Repair Techniques 17,20,21

\begin{tabular}{|c|c|c|c|c|}
\hline Surgical technique & $\begin{array}{l}\text { Patient age } \\
\text { (years) }\end{array}$ & $\begin{array}{l}\text { Early mortality } \\
(\%)\end{array}$ & $\begin{array}{l}\text { Late mortality } \\
(\%)\end{array}$ & $\begin{array}{l}\text { Reoperation } \\
(\%)\end{array}$ \\
\hline Brom repair (three-patch) & 5.2 & 0 & 0 & 0 \\
\hline Doty repair (two-patch) & 5.2 & 0 & 24 & $0-29$ \\
\hline McGoon (one-patch) & 5.2 & 0 & $?$ & 62 \\
\hline $\begin{array}{l}\text { Myer's autologous sliding } \\
\text { aortoplasty }\end{array}$ & 7.6 & 7.7 & 0 & 0 \\
\hline
\end{tabular}

WS might present with pure mitral regurgitation. Bruno et al. ${ }^{17}$ found that the concomitant severe SVAS in WS patients might exaggerate the mitral regurgitation. Bajracharya et al. ${ }^{36}$ recommended that mitral valve repair including chord, leaflet and annulus plasties could be the treatment of choice for mitral valve prolapse in WS patients.

\section{Atypical cardiac defects}

Pober ${ }^{1}$ indicated that intracardiac lesions are uncommon in WS patients. It is a common idea by Nakamoto et al. ${ }^{39}$, Shimamoto et $a l .{ }^{40}$ and Park et al. ${ }^{41}$ that these atypical heart defects usually warrant concurrent surgical repair. The associated defects and management were listed in Table III.

\section{Surgical indications}

It was reported by Eronen et al. ${ }^{26}$ that $61 \%$ of the infantile WS patients required surgery or intervention. Based on a study by Del Pasqua et al. $^{6}$, the surgical indications included SVAS tended to progress, especially when the Doppler gradient was above $30 \mathrm{mmHg}$, and gradients over $50 \mathrm{mmHg}$. They also stated that cardiac catheterization with coronary angiography was necessary for demonstrating coexistence of coronary arterial anomalies and decreased coronary flow prior to surgery. Stamm et al. ${ }^{27}$ stated that aortic arch surgery could be performed safely and with excellent early and late results in children with SVAS. However, Eronen et $a l .{ }^{26}$ found that aortoplasty or aortic angioplasty might cause postoperative mild to moderate aortic valve insufficiency and mild restenosis. Another postoperative concern as indicated by Gray et al. ${ }^{14}$ was the recurrent pseudoaneurysm after surgical correction of SVAS, which was considered the abnormal quality of the vascular tissue in WS patients. Del Pasqua et al. ${ }^{6}$ revealed that balloon angioplasty could be effective, with or without the placement of stents, for WS patients with peripheral pulmonary stenosis, particularly distal stenosis. De Rubens Figueroa et al. ${ }^{3}$ reported that, in $58 \%$ of cases, a surgical operation was required, depending on the severity of pulmonary artery stenosis. Geggel et al. ${ }^{29}$ reported that balloon dilation of peripheral pulmonary stenosis in WS were 134 dilation maneuvers during 39 procedures in 25 patients with a success rate for initial dilations of $51 \%$. Bruno et al. ${ }^{17}$ proposed, in cases of pulmonary artery branch stenosis, there was the possibility of stent placement. However, restenosis occurred in two children after pulmonary artery reconstruction. Patients with pulmonary artery stenosis, in the absence of other significant cardiovascular abnormalities, were often managed conservatively. Gray et al. ${ }^{14}$ indicated that, if treatment was required, balloon angioplasty could be used for discrete stenosis of the distal pulmonary arteries, but surgery was often necessary with longsegment disease or discrete stenosis in the main pulmonary artery. They also pointed out that patient with aneurysmal dilation of the main pulmonary artery might be at risk of obstruction of the coronary ostium.

Moreover, Maisuls et al. ${ }^{49}$ suggested, in WS patients, severe mitral regurgitation is indicated for surgical treatment at the ages of 8 and 11 years.

\section{Adverse cardiac events}

Scheiber et al. ${ }^{2}$ reported in an echocardiographic study that SVAS progressed with age, in spite of occasional spontaneous improvement; while De Rubens Figueroa et al. $^{3}$ noted that pulmonary artery branch stenosis tended to improve spontaneously, and Monge et al. ${ }^{28}$ observed the same phenomenon, especially in those with mild to moderate other than those with severe peripheral pulmonary artery stenosis. In contrast to SVAS, pulmonary artery stenosis 
Table III. Atypical Congenital Heart Defects Associated With Williams Syndrome

\begin{tabular}{|c|c|c|c|}
\hline Author & $\begin{array}{l}\text { Patient } \\
\text { number }\end{array}$ & Atypical congenital heart defect & Management \\
\hline Del Pasqua et al. ${ }^{6}$ & 19 & $\begin{array}{l}\text { Tetralogy of Fallot }(n=2) \text {, atrial septal } \\
\text { defect }(n=4) \text {, aortic regurgitation }(n= \\
1) \text {, mitral regurgitation }(n=1) \text {, bicuspid } \\
\text { aortic valve }(n=2) \& \text { ventricular septal } \\
\text { defect }(n=9)\end{array}$ & Follow-up \\
\hline Hanya et al. $^{42}$ & 1 & $\begin{array}{l}\text { Complete atrioventricular septal defect ( } \\
=1 \text { ) }\end{array}$ & Autopsied case \\
\hline Nakamoto et al. ${ }^{39}$ & 1 & $\begin{array}{l}\text { Complete atrioventricular septal defect (n } \\
=1 \text { ) }\end{array}$ & 2-patch technique \\
\hline $\begin{array}{l}\text { Shimamoto et al. }{ }^{40} \text {; } \\
\text { Park et al. }{ }^{41} \text {; Ferrero } \\
\text { et al. }{ }^{43}\end{array}$ & 3 & $\begin{array}{l}\text { Total anomalous pulmonary venous return } \\
(\mathrm{n}=3)\end{array}$ & $\begin{array}{l}\text { Common pulmonary } \\
\text { vein and left atrium } \\
\text { anastomosis, and } \\
\text { chordal reconstruction; } \\
\text { repaired with the } \\
\text { aid of hypothermic } \\
\text { circulatory arrest }\end{array}$ \\
\hline Mazumdar et al. ${ }^{44}$ & 1 & $\begin{array}{l}\text { Double chambered right ventricle }+ \\
\text { coronary artery aneurysms }(n=1)\end{array}$ & Died before surgery \\
\hline Changela et al. ${ }^{5}$ & 1 & Ebstein anomaly & $\begin{array}{l}\text { Follow-up with genetic } \\
\text { counseling }\end{array}$ \\
\hline Williams \& Cook $^{45}$ & 1 & $\begin{array}{l}\text { Ebstein anomaly and severe branch } \\
\text { pulmonary artery stenosis }\end{array}$ & $\begin{array}{l}\text { Palliative care } \\
\text { treatment }\end{array}$ \\
\hline $\begin{array}{l}\text { Pober }{ }^{1} \text {; De Rubens } \\
\text { Figueroa et al. }{ }^{3} \text {; Yau } \\
\text { et al. }{ }^{4} \text {; Nakamoto } \\
\text { et al. }{ }^{39} \text {; Lee et al. }{ }^{46} \text {; } \\
\text { Zalzstein et al. } .^{47} \\
\text { Okagawa et al. } .^{48}\end{array}$ & -- & $\begin{array}{l}\text { Displacement of lung arteries or coronary } \\
\text { arteries }^{3} \text {; narrowing of the aorta, or the } \\
\text { pulmonary, coronary, renal, cerebral, } \\
\text { carotid, brachiocephalic, subclavian, } \\
\text { mesenteric, and intracranial arteries } \\
\text { bilateral Moyamoya disease } 46 \text {; coronary } \\
\text { artery abnormalities }{ }^{47} \text {; splenic artery } \\
\text { stenosis }{ }^{47} \text {; abdominal aortic narrowing } \\
\text { \& pulmonary artery sling }\end{array}$ & -- \\
\hline
\end{tabular}

in this population often regressed or resolved with time. Wessel et al. ${ }^{50}$ reported the pressure gradient decreased spontaneously from a mean of 23 to $9.5 \mathrm{mmHg}$ in $46.9 \%$ (23/49) patients with pulmonary artery stenosis over 14 years. Pober $^{1}$ found that patients with WS were at an increased risk for major adverse cardiac events, and congenital cardiovascular disease was responsible for most of the morbidity associated with WS. A follow-up study by Sugayama et al. ${ }^{51}$ illustrated that major adverse cardiac events occurred after 41 out of 447 procedures $(9 \%)$, including 20 deaths, 25 episodes of postoperative mechanical circulatory support, and 14 postoperative cardiac arrests. SVAS with significant pressure gradients posed sufficient risk of sudden death. Kececioglu et al. ${ }^{52}$ estimated that the risk of sudden death was $3 \%$ in a series of 104 patients with WS followed-up for 30 years. The exact mechanism of major adverse cardiac events in patients with WS was unknown. Hornik et al. ${ }^{53}$ reminded that the major adverse cardiac events were significantly more common after combined left and right outflow tract procedures than after complex left outflow tract or isolated SVAS procedures. Bird et al. ${ }^{54}$ provided with pathological evidences of coronary artery stenosis and severe biventricular outflow tract obstruction as causes of sudden death in 5 of 10 WS patients. Eronen et al. ${ }^{26}$ reported one WS patient without receiving an operation 
died of pneumonia at the age of 4 years, and another died suddenly of heart failure at the age of 4 months due to a misdiagnosis. Myocardial infarctions and sudden death have been reported in childhood, secondary to lesions of coronary dysplasia in cases of WS, however, they were unusual ${ }^{3}$. Surgical relief of either SVAS or more distal arch obstruction might substantially decrease coronary perfusion pressure, in turn, leading to coronary malperfusion ${ }^{53}$. A ventricular arrhythmia generated by an ischemic myocardium was a possible mechanism to explain sudden death in these cases. Collins ${ }^{55}$ documented that arrhythmias might play an important role, because prolongation of the QTc interval were found in a subset of patients with WS. When patients were associated with hypertrophic obstructive cardiomyopathy or left ventricular pressure and volume overload, SVAS and mitral regurgitation occurred at greater risk as shown by Bruno et al. ${ }^{17}$. Additionally, risks of anesthesia included craniofacial features causing difficult ventilation and tracheal intubation, variable reaction to neuromuscular blockade, and endocrine and metabolic disorders, which led to impaired hepatic drug metabolism and poor temperature regulation as have been indicated by Del Pasqua et al. ${ }^{6}$ Moreover, Yuan et al's ${ }^{56}$ follow-up study revealed longterm sequelae of surgical resection, such as recurrence of SVAS, which might warrant reintervention.

Congenital heart defects are commonly seen in WS patients. A large numbers of the patients warrant surgical or interventional therapies. Of them, the surgical treatment of SVAS and coarctation of the aorta poses challenges due to the concerns of long-term outcomes in the patients, probably related to the younger age at operation. For SVAS patients, Brom three-patch technique is praised for its good postoperative results; whereas coarctation of the aorta seems to be refractory due to recoarctation after end-to-end anastomosis and frequent failures of transcatheter balloon commonly leading to aggressive aortoplasty. Care should also be taken as for the development of adverse cardiac events, in particular, in those with no surgical intervention or with no prompt diagnosis. Pathogenesis of congenital heart defects in WS needs to be further studied.

\section{REFERENCES}

1. Pober BR. Williams-Beuren syndrome. N Engl J Med 2010; 362: 239-252.

2. Scheiber D, Fekete G, Urban Z, et al. Echocardiographic findings in patients with Williams-Beuren syndrome. Wien Klin Wochenschr 2006; 118: 538-542.

3. De Rubens Figueroa J, Rodríguez LM, Hach JL, Del Castillo Ruíz V, Martínez HO. Cardiovascular spectrum in Williams-Beuren syndrome: the Mexican experience in 40 patients. Tex Heart Inst J 2008; 35: 279-285.

4. Yau EKC, Lo IFM, Lam STS. Williams-Beuren syndrome in the Hong Kong Chinese population: retrospective study. Hong Kong Med J 2004; 10: 22-27.

5. Changela V, Maheshwari S, Bhat M. Williams syndrome and Ebstein's anomaly: a rare association. Ann Pediatr Card 2009; 2: 165-166.

6. Del Pasqua A, Rinelli G, Toscano A, et al. New findings concerning cardiovascular manifestations emerging from long-term follow-up of 150 patients with the Williams-Beuren-Beuren syndrome. Cardiol Young 2009; 19: 563-567.

7. Burrows P. William's syndrome with coarctation of the aorta and pulmonary stenosis. MyPACS.net: Radiology Teaching Files > Case 7764767. http://www. mypacs.net/cases/WILLIAMS-SYNDROME-WITHCOARCTATION-OF-THE-AORTA-AND-PULMONARYSTENOSIS-7764767.html.

8. Dridi SM, Foucault Bertaud A, Igondjo Tchen S, et al. Vascular wall remodeling in patients with supravalvular aortic stenosis and Williams Beuren syndrome. J Vasc Res 2005; 42: 190-201.

9. Morris CA, Mervis CB. Williams syndrome and related disorders. Annu Rev Genomics Hum Genet 2000; 1: 461-484.

10. Li DY, Toland AE, Boak BB, et al. Elastin point mutations cause an obstructive vascular disease, supravalvular aortic stenosis. Hum Mol Genet 1997; 6: 1021-1028.

11. Ewart AK, Jin W, Atkinson D, Morris CA, Keating MT. Supravalvular aortic stenosis associated with a deletion disrupting the elastin gene. J Clin Invest 1994; 93: 1071-1077.

12. Olson TM, Michels VV, Urban Z, et al. A $30 \mathrm{~kb}$ deletion within the elastin gene results in familial supravalvular aortic stenosis. Hum Mol Genet 1995; 4: 1677-1679.

13. Morris CA. Genetic aspects of supravalvular aortic stenosis. Curr Opin Cardiol 1998; 13: 214-219.

14. Gray JC 3rd, Krazinski AW, Schoepf UJ, et al. Cardiovascular manifestations of Williams syndrome: imaging findings. J Cardiovasc Comput Tomogr 2013; 7: 400-407.

15. Stamm C, Friehs I, Ho SY, Moran AM, Jonas RA, del Nido PJ. Congenital supravalvar aortic stenosis: a simple lesion? Eur J Cardiothorac Surg 2001; 19: 195-202.

16. O'Connor WN, Davis JB Jr, Geissler R, Cottrill CM, Noonan JA, Todd EP. Supravalvular aortic stenosis. Clinical and pathologic observations in six patients. Arch Pathol Lab Med 1985; 109: 179-185. 
17. Bruno E, Rossi N, Thüer O, Córdoba R, Alday LE. Cardiovascular findings, and clinical course, in patients with Williams syndrome. Cardiol Young 2003; 13: 532-536.

18. Fricke TA, d'Udekem Y, Brizard CP, Wheaton G, Weintraub RG, Konstantinov IE. Surgical repair of supravalvular aortic stenosis in children with Williams syndrome: a 30-year experience. Ann Thorac Surg 2015; 99: 1335-1341.

19. Cruz-Castañeda BF, Carrillo-Llamas F, RamosHiguera S, López-Taylor JG, Buen EP. Surgical repair of supravalvular aortic stenosis with use of Brom's technique: short-term results in 9 children. Tex Heart Inst J 2009; 36: 226-229.

20. Kaushal S, Backer CL, Patel S, Gossett JG, Mavroudis C. Midterm outcomes in supravalvular aortic stenosis demonstrate the superiority of multisinus aortoplasty. Ann Thorac Surg 2010; 89: 1371-1377.

21. Myers JL, Waldhausen JA, Cyran SE, Gleason MM, Weber HS, Baylen BG. Results of surgical repair of congenital supravalvular aortic stenosis. J Thorac Cardiovasc Surg 1993; 105: 281-287; discussion 287288.

22. Croti UA, Braile DM, Bodini AL, Oliveira MA. Enlargement of the ascending aorta with Brom technique in a patient with Williams-Beuren syndrome. Rev Bras Cir Cardiovasc 2008; 23: 436-438.

23. Bonini RC, Palazzi EM, Chaccur P, Sousa LC. Supravalvular aortic stenosis surgical repair using modified Sousa's technique. Rev Bras Cir Cardiovasc 2010; 25: 253-256.

24. Valente AS, Alencar P, Santos AN, Lobo RA, Mesquita FA, Guimarães AG. Supravalvular aortic stenosis in adult with anomalies of aortic arch vessels and aortic regurgitation. Rev Bras Cir Cardiovasc 2013; 28: 545549.

25. Deo SV, Burkhart HM, Dearani JA, Schaff HV. Supravalvar aortic stenosis: current surgical approaches and outcomes. Expert Rev Cardiovasc Ther 2013; 11: 879-890.

26. Eronen M, Peippo M, Hiippala A, et al. Cardiovascular manifestations in 75 patients with Williams syndrome. J Med Genet 2002; 39: 554-558.

27. Stamm C, Friehs I, Moran AM, et al. Surgery for bilateral outflow tract obstruction in elastin arteriopathy. J Thorac Cardiovasc Surg 2000; 120: 755-763.

28. Monge MC, Mainwaring RD, Sheikh AY, Punn R, Reddy VM, Hanley FL. Surgical reconstruction of peripheral pulmonary artery stenosis in Williams and Alagille syndromes. J Thorac Cardiovasc Surg 2013; 145: 476-481.

29. Geggel RL, Gauvreau K, Lock JE. Balloon dilation angioplasty of peripheral pulmonary stenosis associated with Williams syndrome. Circulation 2001; 103: 21652170 .

30. Marks JL, Mitchell MB, Campbell DN, Toews WH. Composite aortoplasty for recurrent coarctation after neonatal repair in Williams syndrome. Ann Thorac Surg 2004; 77: 319-321.
31. Mannarino S, Keizman E, Pasotti M, Codazzi AC, De Sando E, Giamberti A. A rare case of discrete aortic coarctation in Williams-Beuren syndrome. Diagnostic and therapeutic considerations. Pediatr Med Chir 2015; 37: pmc.2015.120. doi: 10.4081/pmc.2015.120.

32. Kammache I, Acar P, Kreitmann B, Fraisse A. WilliamsBeuren syndrome: an unusual cause of neonatal and infantile coarctation. J Thorac Cardiovasc Surg 2010; 140: e80-e81.

33. Ar1 ME, Erdoğan İ, Varan B, Özkan M. A rare cardiovascular finding in two cases with Williams syndrome: recurrent coarctation of aorta. Turk Gogus Kalp Damar Cerrahisi Dergisi 2015; 23: 728-731.

34. Apostolopoulou SC, Kelekis NL, Laskari C, Kaklamanis L, Rammos S. Restenosis and pseudoaneurysm formation after stent placement for aortic coarctation in Williams syndrome. J Vasc Interv Radiol 2002; 13: 547-548.

35. Zanjani KS, Sabi T, Moysich A, et al. Feasibility and efficacy of stent redilatation in aortic coarctation. Catheter Cardiovasc Interv 2008; 72: 552-556.

36. Bajracharya P, Bhatnagar S, Pauliks LB. Mitral valve diseases in Williams syndrome-case report and review of the literature. Echocardiography 2011; 28: E156-E159.

37. Hallidie-Smith KA, Karas S. Cardiac anomalies in Williams-Beuren syndrome. Arch Dis Child 1988; 63: 809-813.

38. Takagi H, Mori $\mathrm{Y}$, Iwata $\mathrm{H}$, et al. Mitral regurgitation without supravalvular aortic stenosis in Williams syndrome. Heart Vessels 2002; 16: 257-259.

39. Nakamoto S, Saga T, Shinohara T. Williams syndrome associated with complete atrioventricular septal defect. Heart 2003; 89: e15.

40. Shimamoto T, Ikeda T, Koshiji T, et al. A successful surgical repair of total anomalous pulmonary venous connection associated with Williams syndrome. Kyobu Geka 1997; 50: 405-408.

41. Park HK, Heinle JS, Morales DL. Williams syndrome and obstructed total anomalous pulmonary venous return: a previously unreported association. Ann Thorac Surg 2012; 94: 289-291.

42. Hanya S, Natsuaki M, Morikawa T, Tatsuno K, Imai Y. Case of supravalvular aortic stenosis syndrome associated with complete endocardial cushion defect. Kyobu Geka 1974; 27: 425-432.

43. Ferrero GB, Biamino E, Sorasio L, et al. Presenting phenotype and clinical evaluation in a cohort of 22 Williams-Beuren syndrome patients. Eur J Med Genet 2007; 50: 327-337.

44. Mazumdar J, Sarkar R, Badveli A, Majumder B. Double chamber right ventricle in Williams syndrome: a rare cardiac anomaly reported. Springerplus 2016; 5: 275.

45. Williams DA, Cook AL. An infant with Williams-Beuren syndrome and Ebstein anomaly. Cardiol Young 2010; 20: 445-447.

46. Lee HS, Shin DI, Lee EJ, et al. A case of bilateral Moyamoya disease associated with Williams syndrome. Neurology Asia 2010; 15: 173-177. 
47. Zalzstein E, Moes CA, Musewe NN, Freedom RM. Spectrum of cardiovascular anomalies in WilliamsBeuren syndrome. Pediatr Cardiol 1991; 12: 219-223.

48. Okagawa H, Kimura K, Okuno M, Hattori M, Nakagawa M. Case of Williams elfin facies syndrome with pulmonary artery sling. Int J Cardiol 1993; 42: 295297.

49. Maisuls H, Alday LE, Thüer O. Cardiovascular findings in the Williams-Beuren syndrome. Am Heart J 1987; 114(4 Pt 1): 97-99.

50. Wessel A, Pankau R, Kececioglu D, Ruschewski W, Bürsch JH. Three decades of follow-up of aortic and pulmonary vascular lesions in the Williams-Beuren syndrome. Am J Med Genet 1994; 52: 297-301.

51. Sugayama SM, Moisés RL, Wagënfur J, et al. WilliamsBeuren syndrome: cardiovascular abnormalities in 20 patients diagnosed with fluorescence in situ hybridization. Arq Bras Cardiol 2003; 81: 462-473.
52. Kececioglu D, Kotthoff S, Vogt J. Williams-Beuren syndrome: a 30-year follow-up of natural and postoperative course. Eur Heart J 1993; 14: 1458-1464.

53. Hornik CP, Collins RT 2nd, Jaquiss RD, et al. Adverse cardiac events in children with Williams syndrome undergoing cardiovascular surgery: An analysis of the Society of Thoracic Surgeons Congenital Heart Surgery Database. J Thorac Cardiovasc Surg 2015; 149: 15161522.e1.

54. Bird LM, Billman GF, Lacro RV, et al. Sudden death in Williams syndrome: report of ten cases. J Pediatr 1996; 129: 926-931.

55. Collins RT 2nd. Clinical significance of prolonged QTc interval in Williams syndrome. Am J Cardiol 2011; 108: 471-473.

56. Yuan SM, Kuperstein R, Lavce J. Progressive discrete subaortic stenosis developed after successful primary repair of the supravalvular aortic stenosis in Williams syndrome. Cardiol J 2009; 16: 368-371. 